\title{
BARGAINING POWER AND ENFORCEMENT IN CREDIT MARKETS
}

\author{
GARANCE GENICOT AND DEBRAJ RAY
}

\begin{abstract}
In a credit market with enforcement constraints, we study the effects of a change in the outside options of a potential defaulter on the terms of the credit contract, as well as on borrower payoffs. The results crucially depend on the allocation of "bargaining power" between the borrower and the lender. We prove that there is a crucial threshold of relative weights such that if the borrower has power that exceeds this threshold, her expected utility must go up whenever her outside options come down. But if the borrower has less power than this threshold, her expected payoff must come down with her outside options. In the former case a deterioration in outside options brought about, say, by better enforcement, must create a Lorenz improvement in state-contingent consumption. In particular, borrower consumption rises in all "bad" states in which loans are taken. In the latter case, in contrast, the borrower's consumption must decline, at least for all the bad states. These disparate findings within a single model permit us to interpret existing literature on credit markets in a unified way.
\end{abstract}

Date: December 2004

This paper is dedicated to Pranab Bardhan with respect and admiration. Ray acknowledges support from the National Science Foundation. We are grateful to STICERD at the London School of Economics for warm hospitality during the writing of this paper. 


\section{INTRODUCTION}

Problems of enforcement are central to the functioning of credit markets. While the difficulties of ensuring repayment are endemic in all societies, developing countries are particularly vulnerable. In such countries, there is often little reliance on a court of law and equally little faith in the ability to seize collateral. Usually, the main deterrent to default is the threat that no future loans will be forthcoming, sometimes enhanced by the fear of community sanctions. This constraint often seriously limits the extent of consumption smoothing individuals have access to.

In this paper, we study how a change in enforcement - or more generally, in the outside options of a potential defaulter - affects the terms of the credit contract, as well as equilibrium payoffs. It will turn out that the results crucially depend on the allocation of "bargaining power" between the borrower and the lender. ${ }^{1}$

In the model that we construct, risk-averse agents borrow from risk-neutral lenders to smooth their consumption. At any point in the process, the borrower may default on an existing loan. In that case the borrower is excluded from the current relationship and has access to some outside option. Any loan arrangement must respect this enforcement constraint. Just which arrangement will prevail depends, of course, on the effective relative weights afforded to lender and borrower payoffs - on "bargaining power", to put it briefly.

We prove that there is a crucial threshold of relative weights such that if the borrower has power that exceeds this threshold, her expected utility must go up whenever her outside options come down. But if the borrower has less power than this threshold, her expected payoff must come down with her outside options. In particular, the first result holds in a competitive credit market (where the borrower receives the entire implicit weight), and the second result applies when the lender is a monopolist (so that the borrower has no power at all).

The changes also have implications for the shape of the consumption function. When borrowers "have the power", a deterioration in outside options brought about, say, by better punishment opportunities, must create a Lorenz improvement in state-contingent consumption. In particular, borrower consumption rises in all "bad" states in which loans are taken. In contrast, when lenders have the power, a borrower's consumption must decline, at least for all the bad states. While inequality comparisons are decidedly ambiguous now, there is certainly no presumption of a Lorenz improvement.

These findings permit us to re-read existing literature on credit markets in a unified way. In particular, we focus on two papers. Krueger and Perri (2003) attempt to explain why consumption inequality in the United States has declined

\footnotetext{
${ }^{1}$ The concluding section provides some brief bibliographical notes on recent literature that emphasizes bargaining power in relationships.
} 
despite a rise in income inequality. They do so using a model of credit with enforcement constraints in which borrowers have all the power. In the specific case they consider, borrower payoffs improve, especially in bad states. Kranton and Swamy (1998) also study credit markets, this time in the nineteenth century Bombay Deccan. They view the introduction of the British court system in India as an improvement in enforcement technology, and describe its effect on credit markets. Their main observation - that borrower payoffs declines in bad states, stands in apparent contrast to the Krueger-Perri observation. We show that these two papers are fundamentally looking at the same issue, but arrives at contrasting results because the implicit assumptions on bargaining power are different in the two cases (yet in our opinion, correct in each of their specific contexts).

\section{Credit Markets with Self-Enforcement}

2.1. Basic Model. There are two types of agents, lenders and potential borrowers. At any date, a borrower receives income $y$ that assumes one of a finite number of conceivable values in some set $S$. Value $y$ is realized with probability $p(y)$. Income realizations are independent and identical, over people as well as dates.

Lenders are risk-neutral. Their payoff is simply discounted expected profit. All borrowers have the same one-period von Neumann-Morgenstern utility function $u$ defined on consumption. Their lifetime (discount-normalized) expected utility from any date $t$ onwards is given by

$$
(1-\delta) \mathbf{E} \sum_{j=0}^{\infty} \delta^{j} u\left(c_{t+j}\right),
$$

where $u$ is increasing, smooth and strictly concave, and $\delta \in(0,1)$. Individuals have access to a credit market to smooth consumption. The combination of loans that an individual receives or repayment that he makes when his income is $y$ results in a level of consumption $c(y)$. A consumption allocation $\mathbf{c}$ is a nonnegative vector of consumptions $\{c(y)\}_{y \in S}$. Note that we are looking at consumption allocations that are stationary and history independent, but our main results are not significantly changed by using these extended contracts.

2.2. Self-Enforcing Allocations. At any point of time, a borrower might choose to avoid the specified repayment $y-c(y)$ and consequently default on the loan. So we study loan arrangements that are self-enforcing. To this end, consider the expected continuation utility $\underline{u}$ of a borrower if she reneges on her credit arrangement. In general, this will depend on the outside option of the borrower as she looks for other credit relationships, diminished by any sanctions or punishments that the lender can credibly mete out. 
Say that an allocation $\mathbf{c}$ is self-enforcing if for all $y \in S$,

$$
(1-\delta) u(c(y))+\delta \sum_{y} p(y) u(c(y)) \geq(1-\delta) u(y)+\delta \underline{u} .
$$

2.3. The Allocation of Power. Turn now to a detailed description of the credit relationship between a lender and borrower. The specific arrangement that they will agree on depends on the allocation of power between them. Let $u_{o}$ be the utility the borrower can expect if he does not agree on an allocation with this lender. $u_{o}$ is just the same as $\underline{u}$ (see above) if no additional punishment can be meted out for default; otherwise it is larger by precisely the utility value of such punishment.

We identify the allocation of power with the implicit welfare weights on the utility of the two parties, which in turn determines the allocation of the joint surplus. Equivalently, one might identify the allocation of power with the choice of a particular point on the (constrained) utility possibility frontier. Neither shorthand does justice to the actual process which might mirror the allocation of power, such as the offers and counteroffers made. Nevertheless, we do not need this extra structure as long as we agree that "more power" to an agent slides us up the constrained frontier in the direction of that agent, or pivots relative welfare weights in her direction.

Denote by $\alpha \in[0,1]$ the welfare weight on the borrower's utility. Perfect competition (with some constant-profit constraint on lenders) corresponds to the case where all the power is given to borrowers $(\alpha=1)$, while in the case of pure monopoly borrowers possess a zero implicit welfare weight relative to lenders $(\alpha=0)$.

Given some allocation of power $\alpha$, the following incentive-constrained optimization problem describes the appropriate outcome:

[THE $\alpha$-PROBLEM.]

$$
\max _{\mathbf{c}} W\left(\underline{u}, u_{o}\right) \equiv \alpha \sum_{y} p(y) u(c(y))+(1-\alpha) \sum_{y} p(y)[y-c(y)]
$$

subject to the incentive constraint (1) and the participation constraints

$$
\begin{aligned}
& \sum_{y} p(y)[y-c(y)] \geq 0 \\
& \sum_{y} p(y) u(c(y)) \geq u_{o}
\end{aligned}
$$

For any $\alpha$, this problem has a unique solution (see Lemma 1 in appendix) that we shall denote $\mathbf{c}^{*}$. The constrained optimal allocation $\mathbf{c}^{*}$ is characterized by the 
first-order conditions

$$
\frac{\lambda+1-\alpha}{u^{\prime}(c(y))}=\alpha+\beta+(1-\delta) \frac{\gamma_{y}}{p(y)}+\delta \sum_{y^{\prime}} \gamma_{y}^{\prime}
$$

where $\lambda$ is the multiplier on the zero-profit condition (3), $\beta$ the multiplier on the borrower's participation constraint (4), and $\gamma_{y}$ the multiplier on the selfenforcement constraint (1) when realized income is $y$.

It follows that if no enforcement constraint binds then a borrower's consumption is kept constant across states: $c(y)=c$ for all $y$. The particular consumption level will be pinned down by either of the participation constraints (the one that binds) or by the condition $u^{\prime}(c)=(1-\alpha) / \alpha$ for all $y$ if no participation constraint binds. When some (but not all) enforcement constraints bind, equation (5) tells us that consumption is kept constant in all states for which (1) is not binding. Using this information, it is easy to see that if (1) is binding at some value of $y$, it must be binding for all higher income realizations, so that — using (1) again - equilibrium consumption has a "flat" component for low incomes and an increasing component at all higher incomes.

Denote by $v \equiv \sum_{y} p(y) u\left(c^{*}(y)\right)$ the borrower's expected utility from $\mathbf{c}^{*}$ and by $\pi \equiv \sum_{y} p(y)\left[y-c^{*}(y)\right]$ the corresponding expected profit for the lender.

\section{An Improvement in EnForCEMENT}

We now turn to the consequences of an improvement in enforcement capabilities. Such an improvement may simply be viewed as lowering $\underline{u}$, so that the utility cost of a deviation is now higher. To be sure, if such a change stems from a change in the borrower's outside options, $u_{o}$ will change as well.

We study both the effects on borrower payoffs as well as on the form of the equilibrium loan arrangement.

3.1. Borrower Payoffs. Consider, then, an exogenous decrease in $\underline{u}$. The problem is only interesting when at least one of the incentive constraints binds, and there is a non-trivial credit arrangement $c^{*}(y) \neq y$ for at least some $y$. We only consider such cases.

The problem is also uninteresting if the participation constraint of the borrower binds, for then the payoff of the borrower is simply $u_{o}$ by definition. Fortunately, we know that if punishments are small the borrower's participation constraint will be superseded by the self-enforcement constraints, and will not bind.

We claim that there is a borrower's "power threshold" below which $v$ must decrease with $\underline{u}$, while above that threshold $v$ and $\underline{u}$ move in opposite directions. 
Proposition 1. Assume that the borrower's participation constraint is not binding, but that one or more of her incentive constraints do bind. Then there exists $\widehat{\alpha}$ such that if $\underline{u}$ decreases, $v$ increases for all $\alpha \geq \widehat{\alpha}$, stays constant when $\alpha=\widehat{\alpha}$ and decreases for all $\alpha<\widehat{\alpha}$.

Proof. Below, we study two cases, one in which the participation constraint of the lender does not bind and the other in which it does. Subsequently, we connect these cases to the various values of $\alpha$.

Because the $\alpha$-problem has a unique solution for every $\alpha$, this solution must be continuous in the parameter $\underline{u}$. It therefore suffices to consider only those changes in $\underline{u}$ such that exactly the same constraints bind before and after. Once this is done, the general assertion follows by simply piecing together the local effects deduced below.

At any state $y$ for which the enforcement constraint is not binding, the first order conditions (5) tell us that

$$
\frac{\lambda+1-\alpha}{u^{\prime}(c(y))}=\alpha+\delta \sum_{y^{\prime}} \gamma_{y}^{\prime},
$$

remembering that the borrower's participation constraint is not binding by assumption.

Now suppose that the lender's participation constraint is not binding, so that $\lambda=0$. We claim that in this case, a decrease in $\underline{u}$ results in a decrease in $v$.

Lemma 2 in the appendix shows that $\sum_{y^{\prime}} \gamma_{y}^{\prime}$ is increasing in $\underline{u}$. [Intuitively, the enforcement constraints become tighter overall as post-deviation options improve.] In conjunction with (6), this implies that in any non-binding state $y, c(y)$ decreases upon a decline in $\underline{u}$.

Now suppose, contrary to our claim, that $v$ has not decreased. Consider any state $y$ in which the enforcement constraint (1) is binding. Recall that constraint (1), which we write here as

$$
(1-\delta)[u(y)-u(c(y))]=\delta[v-\underline{u}] .
$$

Because $v$ is presumed not to have decreased, $v-\underline{u}$ must have increased. We see, then, that $u(y)-u(c(y))$ increases for all these binding states, which is just to say that $c(y)$ must decline for all such states.

It follows that consumption decreases in all states, whether or not the constraint is binding. But this contradicts our supposition that $v$ has not decreased, and completes the proof of the claim in this case.

Next, consider a situation in which the lender's profit constraint is binding. In this case, average consumption equals average income. Since a decrease in $\underline{u}$ strictly 
relaxes any binding incentive constraint and profit stays constant, the borrower's expected utility $v$ must go up.

Now we connect the two cases to values of $\alpha$. Lemma 3 in the appendix does just that: it shows that if for some $\alpha$ the lender's participation constraint binds then it does also bind for any higher $\alpha$. To put the final arguments in place, denote as $\underline{\alpha}$ the threshold $\alpha$ such that for all $\alpha \geq \underline{\alpha}$ the lender's participation constraint binds. We saw that, for any $\alpha<\underline{\alpha}, v$ decreases and $\pi^{*}$ increases following a reduction in $\underline{u}$. It follows that, if the non-negative constraint was not binding before the decrease in $\underline{u}$, it won't be binding after. We also saw that if the profit constraint binds before and after the decrease in $\underline{u}$, then $v$ increases. Hence, there remains one possibility to study: for some values of $\alpha$ the non-negative profit constraint binds before but not after the decrease in $\underline{u}$.

In this case, $v$ can increase or decrease. However, given Lemma 3 and the fact that the Pareto frontier is smooth and strictly concave, there exists $\widehat{\alpha}$ such that the following is true. If $\underline{u}$ decreases, $v$ increases for all $\alpha \geq \widehat{\alpha}$, stays constant at $\alpha=\widehat{\alpha}$ and decreases for all $\alpha<\widehat{\alpha}$. It is easy to see that $0<\widehat{\alpha}<1$.

The effect of a decrease in $\underline{u}$ is illustrated in Figure 1. The two constrained payoff frontiers correspond to outside options $\underline{u}$ and $\underline{u}^{\prime}$, and of course the frontier with the lower outside option lies further out from the origin. The welfare weight $\alpha$ is captured by the common slope of the parallel straight lines, which track the outcomes before and after the change. In the case considered in Figure 1, the lender's participation constraint is not binding. Proposition 1 proves that a decline in $\underline{u}$ in this case must lead to a decrease in borrower payoffs, and this is captured in the diagram.

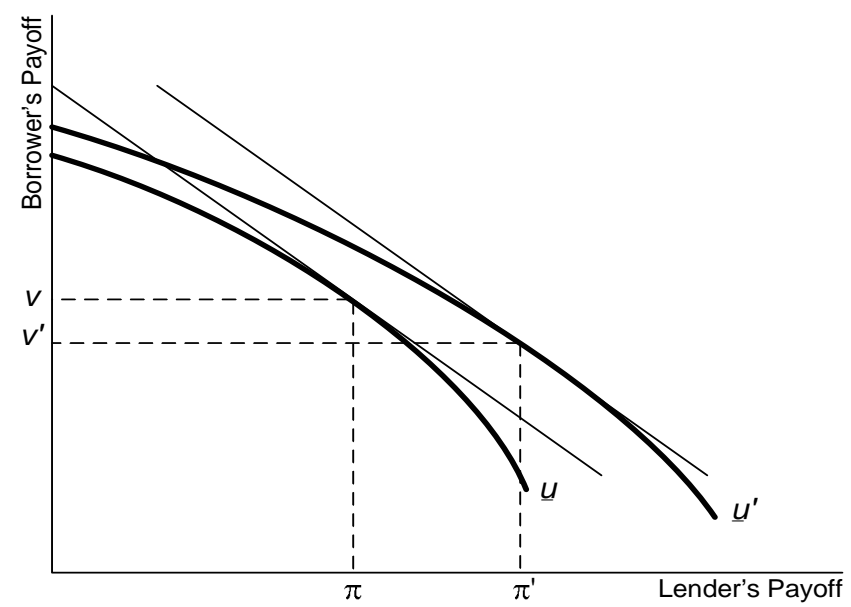

Figure 1. Effect of A Decline In $\underline{u}$ On PAyOfFs 
At the same time, notice that the efficient frontier does not flatten out entirely as it hits the vertical axis. For values of $\alpha$ that fall short of the absolute value of this slope at the axis, the lender's profit constraint must bind. It is now easy to see that borrower payoffs must climb following a reduction in $\underline{u}$.

3.2. The Consumption Profile. Now we explore a related but distinct question: what happens to the consumption profile when post-deviation outside options decline for the borrower? As in the previous section, we take it that the borrower's participation constraint is slack but that one or more of her enforcement constraints do bind.

Proposition 2. For any $\alpha \geq \widehat{\alpha}$, state-contingent borrower consumption becomes "smoother" following a decrease in $\underline{u}$ : it increases for an interval of lower incomes, and decreases for the remaining interval of higher incomes.

Proof. We know that for $\alpha \geq \widehat{\alpha}, v$ increases or stays constant. Now consider a decrease in $\underline{u}$ from $\underline{u}$ to $\underline{u}^{\prime}<\underline{u}$. Let $\mathbf{c}$ and $\mathbf{c}^{\prime}$ be the respective constrained optimal allocations, and $v$ and $v^{\prime}$ be the borrowers' expected utility under these allocations.

Pick any value of income, say $y_{1}$, such that $c^{\prime}\left(y_{1}\right) \geq c\left(y_{1}\right)$. Then, because $v^{\prime}-\underline{u}^{\prime}>v-\underline{u}$, (1) cannot be binding under the new parameters. From our discussion at the end of Section 2.3, it follows that (1) must not bind either (in the new situation) for all $y \leq y_{1}$. Because consumptions are equalized over all nonbinding states, we may conclude that

$$
c^{\prime}(y)=c^{\prime}\left(y_{1}\right) \text { for all } y \leq y_{1}
$$

At the same time, we know (again see Section 2.3) that the consumption function is nondecreasing, so that $c\left(y_{1}\right) \geq c(y)$ for all $y \leq y_{1}$. Combining this information with (7), we conclude that

$$
c^{\prime}(y) \geq c(y) \text { for all } y \leq y_{1} .
$$

However, it cannot be that $c^{\prime}(y) \geq c(y)$ for every $y$, for then no enforcement constraint would bind for the borrower. So, if interpreting $y_{1}$ above as the largest income for which $c^{\prime}\left(y_{1}\right) \geq c\left(y_{1}\right)$, then higher realizations of income must exist and $c^{\prime}(y)<c(y)$ for all such realizations.

The comparison of the two consumption functions implied by Proposition 2 is illustrated in Figure 2. The consumption profile is smoother when borrowers have sufficient bargaining power. When the reduction in $\underline{u}$ stems from better enforcement capabilities, every measure of consumption inequality that is compatible with the Lorenz criterion must necessarily register a decline. Indeed, this is true of any decline in $\underline{u}$ that does not stem from a change in the underlying stochastic process that generates incomes. 
To be sure, if the change in outside options stems from some change in the income generating process itself (such as greater income uncertainty), then Proposition 2 does not necessarily translate into Lorenz-comparisons of consumption before and after. We return to this point in Section 4.1 below.

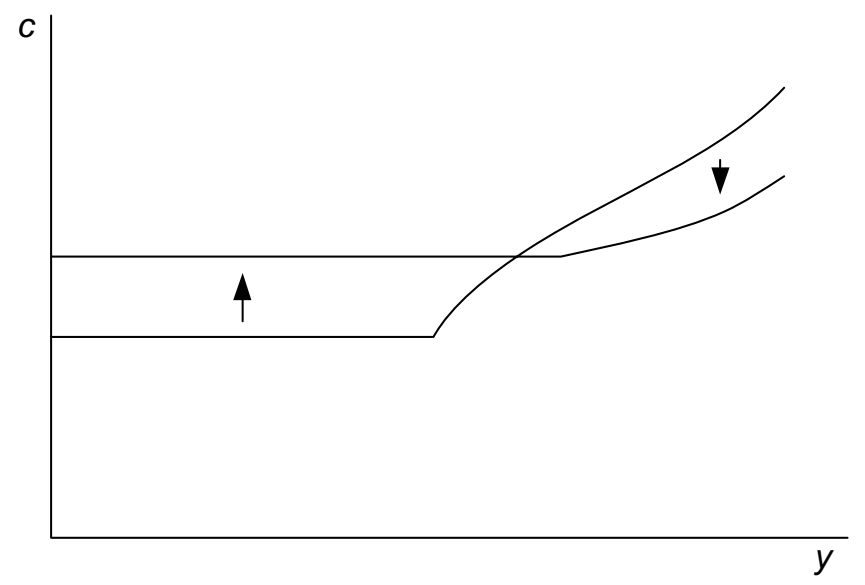

\section{Figure 2. EfFect of A Decrease in $\underline{u}$ on Consumption}

The smoothing result stands in stark contrast to situations in which the lender has the power.

Proposition 3. Suppose that the borrower's participation constraint does not bind. For any $\alpha<\widehat{\alpha}$, state-contingent borrower consumption must decline in every "low income" state, following a decrease in $\underline{u}$. That is, consumption must fall in all states in which the enforcement constraint was not binding to start with.

Proof. We have $\alpha<\widehat{\alpha}$, so that $\underline{u}$ and $v$ move in the same direction and the lender's participation constraint does not bind. Consequently, we may write the first-order constraint (5) as

$$
\frac{1-\alpha}{u^{\prime}(c(y))}=\alpha+\delta \sum_{y^{\prime}} \gamma_{y}^{\prime},
$$

(remembering that the borrower's participation constraint also does not bind, by assumption).

Lemma 2 in the appendix shows that $\sum_{y^{\prime}} \gamma_{y}^{\prime}$ decreases along with $\underline{u}$. Therefore (9) immediately shows us that $c^{\prime}(y)<c(y)$ for all nonbinding states.

This and the first order conditions in (5) imply that, in any state $y$ in which the incentive constraint (1) does not bind, $c(y)$ decreases following a decline in $\underline{u}$. 
Just as Proposition 1 shows that borrower payoff may move in different directions depending on the allocation of power, Propositions 2 and 3 highlight the contrast in consumption profiles. In the former case, a lower outside option gives a "powerful" borrower greater credibility and allows her to smooth her consumption better. In the latter case, a lower outside option gives a "powerful" lender a greater ability to extract surplus from the borrower, so that she is protected less in bad states. [To our understanding, the change in consumption under "good" states is ambiguous.]

\section{Two Applications}

4.1. Income and Consumption Inequality in the United States. Krueger and Perri (2003) - KP hereafter - investigate the relationship between the crosssectional distribution of income and consumption in the United States between 1980 and 1997. They present evidence that the Gini coefficient of after-tax labor income increased while the consumption Gini remained roughly constant.

KP observe that there are two ways to interpret the cross-sectional income distribution; one, as persistent income differences across individuals or households, and two, as an increase in the spread or volatility of incomes. They adopt the latter view, and use the increased spread in the agent's income distribution as a possible explanation for the consumption observations. They use a specific example of risk-sharing without commitment. Consider pairs of agents whose endowments are perfectly negatively correlated and take on just two values: $h$ and $\ell$, with $h>\ell>0$. The agents have constant relative risk aversion and, across pairs, their income distributions are multiples of each other. In this case, when risk-sharing is not perfect, $\mathrm{KP}$ show that an increase in the dispersion in the agents' income increases both the Gini measure of income inequality and the level of risk-sharing among the agents. An increase in income dispersion can then result in a simultaneous decrease in the consumption Gini and an increase in the income Gini.

The KP argument easily translates into our more general setting, in a situation where credit markets are competitive. In that case lenders always receive the competitive profit (zero by normalization), so that $\alpha$ is effectively 1 . Then a reduction in post-deviation outside options increases borrower's payoff and smooths out consumption relative to income realizations.

To be sure - and as we have noted above - the smoothing of consumption relative to income may not imply a fall in consumption inequality if the income process itself changes. But as the following discussion shows, one can go a bit further.

Consider a mean-preserving spread in the income distribution in which the lowest possible income realization - call it $y$ — decreases by a small amount $\epsilon>0$, while the other income realizations are increased by $\epsilon d y$ for $y>\underline{y}$. Maintain means: 
$\sum_{y>y} p(y) d y=p(\underline{y})$. [Notice that when income takes on just two values: $\bar{y}$ with probability $p$ and $y$ with probability $(1-p)$, then there is only one possible such change: a decrease in $y$ by an $\epsilon$ compensated by an increase in $\bar{y}$ by $\epsilon(1-p) / p$.] If the post-deviation outside option is given by autarky, then $\underline{u}$ equals $\sum_{y} p(y) u(y)$, and it surely declines.

Assume that a nontrivial borrowing scheme exists to start with (i.e., $\mathbf{c} \neq \mathbf{y}$ ). Now consider the deviation payoffs in each state with income $y$. They are given by

$$
(1-\delta) u(y)+\delta \sum_{z} p(z) u(z)
$$

For states other than the one with lowest income, the direction in which these expressions change is ambiguous. Although continuation utility declines, incomes in states other than $y$ increase. However, Lemma 4 in the Appendix shows that for small $\epsilon$ there is a mean-preserving spread in income as described such that every expression of the form (10) must decline with the change.

Therefore all enforcement constraints are relaxed, and such a mean-preserving spread has the same effect as an improvement in enforcement in the sense of Section 3. Moreover because we are in the competitive case with zero lender profit, expected consumption equals expected income (which remains unchanged under the mean-preserving spread). Now we can follows the same steps in the proof of Proposition 2 to show that consumption patterns must display a Lorenz-improvement. An increase in income inequality — as measured by any Lorenz consistent inequality measure - results in a decrease in consumption inequality.

4.2. Moneylending and Legal Enforcement in the Bombay Deccan. Kranton and Swamy (1998) — KS hereafter — provide evidence that moneylenders in the nineteenth century Bombay Deccan were essentially local monopolists. Initially, they had little or no recourse to legal enforcement of debts. But the introduction of civil courts in colonial India changed that. In particular, it constituted an improvement in enforcement technology in credit markets. KS go on to argue that this institutional change resulted in a lower payoffs to borrowers, at least in bad states, and caused widespread social unrest. Here we have an instance of a change that is essentially the same as the one in KP, yet the effect of that change is very different.

Our model traces this difference to the implicit allocation of power in the two scenarios. In KP the market is assumed to be competitive, with a constant-profit condition imposed on lenders. In KS lenders are local monopolists. Proposition 3 in Section 3.2 shows that indeed an improvement in enforcement must reduce borrower consumption in all nonbinding states, in sharp contrast to the result obtained in Proposition 2. Indeed, we show in Proposition 1 that we can actually sign the effect on the unconditional expected utility of such an institutional change, 
not just the utility conditional on bad states. While $\mathrm{KS}$ do not make such a claim, this possibility is not entirely without foundation. In this context, Dube's (1998) account of the 1856 British settlement of land property rights in Awadh is instructive:

Though pre-British Awadh was far from idyllic ... the bulk of historical evidence indicates that the condition of the peasantry worsened greatly under colonial rule. The crucial difference between the two periods was that in the pre-colonial agrarian system rights to land and its produce were far more dispersed, restraining the zamindars' depredations. In contrast, under the British the zamindars acquired near-absolute power. While during the semi-feudal system prevailing earlier, they had to rely on force and social hierarchy to wring revenue from the peasantry, they now enjoyed ownership of virtually every inch of arable land, the legal power to fix rents and eject tenants, and the backing of the colonial state power.

So is entirely reasonable to suppose that not only do borrower payoffs come down in bad states, they may come down unconditionally. That said, KS's study of the Bombay Deccan is an appropriate context to bring up the question of endogenous bargaining power. Absolute rights to land may not extend to absolute rights to a pool of borrowers, though the presence of interlinked contracts certainly suggests a strong connection. Therefore we briefly comment on the issue of lender entry.

Consider a credit market with a monopolist lender and a fall in $\underline{u}$. This improvement in enforcement increases the profit of a monopolist lender. Consequently, as KS argue, by making the enforcement technology available to anyone willing to be a moneylender, fresh entry may be encouraged. Whether such entry would, in fact, occur and would then nullify the predicted decline in borrowers' utility will depend on the precise nature of inter-lender competition.

For instance, if there is "pure" Bertrand competition (or limited product differentiation) following entry, lender profits would fall substantially. In this case, our assertions regarding a decline in unconditional expected utility will need to be qualified. If, on the other hand, there are either fixed cost of entry or substantial niche markets for credit, the decreased expected utility prediction is one that we can be more confident about. ${ }^{2}$ Note, however, that even fresh entry is consistent with the strong version of our story provided that there are matching frictions as in Diamond (1971).

\footnotetext{
${ }^{2}$ See, e.g., Ray and Sengupta (1989), Floro and Yotopoulos (1991) and Mansuri (1997) on interlinked contracts and market segmentation.
} 


\section{Concluding Remarks}

We study a model of credit markets with limited enforcement, where our main focus is on the bargaining power of the lender relative to the borrower. We show that a change in outside options for the borrower (brought about, say, through a change in the technology of enforcement) has sharply different implications for borrower payoffs and consumption patterns, depending on the allocation of power. In particular, we show that if the relative bargaining power of borrowers exceeds some threshold value, their expected payoffs increase following an improvement in enforcement. In contrast, for power below this threshold level, better enforcement lowers borrower payoffs.

A similar contrast applies to borrower consumption patterns. In the "high power" case, consumptions undergo a Lorenz improvement, rising in bad states and falling in good states. Roughly the opposite happens in the "low power" case: borrower consumption in the bad states must fall, though the outcome for good states is ambiguous.

We then show that our model provides a unified reading of different findings in the literature on credit markets with limited enforcement. We illustrate this with a discussion of two papers: Krueger and Perri (2003) on consumption inequality in the United States, and Kranton and Swamy (1999) on credit markets in nineteenth century India.

Our paper is related to a literature that emphasizes the different implications of variations in bargaining power. For instance, viewed as property or control rights, bargaining power lies at the heart of the incomplete contracts literature pioneered by Grossman and Hart (1986) and Hart and Moore (1990), among others. In the context of a principal-agent relationship, Mookherjee (1997) shows that more power to an incentive-constrained agent increases economic surplus (see also Galasso (2004)). Mookherjee and Ray (2002) show, in the context of a dynamic principal-agent relationship with wealth accumulation, that variations in bargaining power lead to substantially different long-run distributions of wealth. Galasso (2004) shows that in contractual relationships with externalities across different agents, final outcomes depend crucially on the power of agents relative to the principal. The current exercise, apart from its distinct focus on credit markets, is methodologically somewhat different in that it studies the differential impact of a change in parameters (the outside options), depending on bargaining power. 


\section{REFERENCES}

[1] Diamond, P., 1971, "A Model of Price Adjustment." Journal of Economic Theory 3, 156-168.

[2] Dube, S., 1998, Words like Freedom, HarperCollins Publishers, New Delhi: India.

[3] Floro, M. and P. Yotopoulos, 1991, Informal Credit Markets and the New Institutional Economics: The Case of Philippine Agriculture. Boulder, CO: Westview Press.

[4] Galasso, A., 2004, "Bargaining Power in Contracting with Externalities." Mimeo.

[5] Grossman, S. and O. Hart, 1986, "The Costs and Benefits of Ownership: A Theory of Vertical and Lateral Integration." Journal of Political Economy 94, 691719.

[6] Hart, O. and J. Moore, 1990, "Property Rights and the Nature of the Firm." Journal of Political Economy 98, 11191158.

[7] Kimball, M., 1988, "Farmer Cooperatives as Behavior Toward Risk." American Economic Review 78, 224-232.

[8] Kocherlakota, N.R., 1996, "Implications of Efficient Risk Sharing without Commitment." Review of Economic Studies 63(4), 595-609.

[9] Krueger, D. and F. Perri, 2003, "Does Income Inequality Lead to Consumption Inequality? Empirical Findings and Theoretical Explanation." mimeo.

[10] Kranton, R.E. and A. Swamy, 1999, "The Hazard of Piecemeal Reform: British Civil Courts and the Credit Market in Colonial India." Journal of Development Economics 58, 1-24.

[11] Ligon, E., Thomas, J. and T. Worrall, 2002, "Mutual Insurance and Limited Commitment: Theory and Evidence in Village Economies," Review of Economic Studies 69 115-139.

[12] Mansuri, G., 1997, "Credit Layering in Rural Financial Markets: Theory and Evidence from Pakistan." Ph.D. Dissertation, Boston University.

[13] Mookherjee, D., 1997, "Informational Rents and Property Rights in Land," in J. Roemer, ed., Property Rights, Incentives and Welfare, New York: MacMillan Press.

[14] Mookherjee, D. and D. Ray, 2002, "Contractual Structure and Wealth Accumulation," American Economic Review 92(4), 818849.

[15] Ray, D. and K. Sengupta, 1989, "Interlinkages and the Pattern of Competition," in P. Bardhan (ed.), The Economic Theory of Agrarian Institutions. Clarendon Press, Oxford.

[16] Thomas, J.P. and T. Worrall, 1988, "Self-enforcing wage contracts." Review of Economic Studies 55, 541-554

[17] Townsend, R.M., 1994, "Risk and Insurance in Village India. "Econometrica 62(3), 539-91.

[18] Udry, C., 1994, "Risk and Insurance in a Rural Credit Market: An Empirical Investigation in Northern Nigeria." Review of Economic Studies 61(3), 495-526. 
In part of what follows, we consider an obvious extension of the $\alpha$-problem with state-specific post-deviation utilities $\underline{\mathbf{u}}=\{\underline{u}(y)\}_{\forall y}$. Then modified incentive constraints would read as

$$
(1-\delta) u(c(y))+\delta v \geq(1-\delta) u(y)+\delta \underline{u}(y) .
$$

Call this the extended $\alpha$-problem.

Lemma 1. For any $\alpha \in[0,1]$, the extended $\alpha$-problem (and in particular, the original $\alpha$-problem) has a unique solution.

Proof. The objective (2) is concave in the consumption vector $\mathbf{c}$, and strictly so for all $\alpha>0$. Moreover, it is easy to check that the set of consumption vectors $\Gamma$ that satisfy the participation constraint of the lenders and borrowers (3) and (4) and the "extended" incentive constraints (11) is convex. So we are done when $\alpha>0$.

Moreover, when (4) or (11) binds - as they must when $\alpha=0-\Gamma$ is strictly convex. To see this, take two distinct vectors of consumption $\mathbf{c}_{1}$ and $\mathbf{c}_{2}$ in $\Gamma$, and let $\mathbf{c}_{\theta}=\theta \mathbf{c}_{1}+(1-\theta) \mathbf{c}_{2}$ for any $\theta \in(0,1)$. Define $u_{i}=\sum_{y} p(y) u\left(c_{i}(y)\right), \pi_{i}=$ $\sum_{y} p(y)\left[y-c_{i}(y)\right]$ for $i \in\{1,2\}, \pi_{\theta}=\sum_{y} p(y)\left[y-c_{\theta}(y)\right]$ and $u_{\theta}=\sum_{y} p(y) u\left(c_{\theta}(y)\right)$.

Since $\mathbf{c}_{1}$ and $\mathbf{c}_{2}$ satisfy the borrower's participation constraint $\theta u_{1}+(1-\theta) u_{2} \geq$ $u_{o}$. By strict concavity of the utility function $u_{\theta}>\theta u_{1}+(1-\theta) u_{2}$, so the borrowers' participation constraint is not binding at $\mathbf{c}_{\theta}$. Using the very same argument we can show that that no incentive constraint can hold with equality at $\mathbf{c}_{\theta}$. Therefore at $\alpha=0$, we have a strictly convex constraint set, and the proof is complete.

Lemma 2. In the $\alpha$-problem, if $\gamma(y)>0$ for some $y$, then $\sum_{y} \gamma(y)$ strictly increases in $\underline{u}$.

Proof. Consider an extended $\alpha$-problem with state-contingent outside options. Denote by $M(\underline{\mathbf{u}})$ the maximized value of the objective in (2) subject to (3), (4), and (11).

Consider two distinct vectors of state specific reservation utilities, $\underline{\mathbf{u}}_{1}$ and $\underline{\mathbf{u}}_{2}$. Let $\mathbf{c}_{1}$ and $\mathbf{c}_{2}$ be the two corresponding constrained optimal allocations (unique by Lemma 1). For any $\theta \in(0,1)$, let $\underline{\mathbf{u}}_{\theta}=\theta \underline{\mathbf{u}}_{1}+(1-\theta) \underline{\mathbf{u}}_{2}$ and $\mathbf{c}_{\theta}=\theta \mathbf{c}_{1}+(1-\theta) \mathbf{c}_{2}$. Using the strict concavity of the utility function, it is possible to see that no incentive or participation constraint of the borrower binds under the allocation $\underline{\mathbf{u}}_{\theta}$.

Now, if some borrower enforcement or participation constraint were in fact binding in either of the two "starting" problems, then $\underline{\mathbf{u}}_{\theta}$ cannot exhibit full smoothing. In this case, borrower utility can clearly be improved relative to $\underline{\mathbf{u}}_{\theta}$, while keeping lender payoff constant. It follows that if $\alpha>0$,

$$
M\left(\underline{u}_{\theta}\right)>\theta M\left(\underline{u}_{1}\right)+(1-\theta) M\left(\underline{u}_{2}\right) .
$$


If $\alpha=0$, then it is trivial to improve lender utility (relative to $\underline{\mathbf{u}}_{\theta}$ ) while continuing to respect all borrower constraints, as they were not binding at $\underline{\mathbf{u}}_{\theta}$. So in any case, (12) must hold. But the strict convexity implicit in (12) tells us that if we restrict ourselves to the special case in which $\underline{\mathbf{u}}=(\underline{u}, \ldots, \underline{u})$, then

$$
\frac{d M(\underline{u}, \ldots, \underline{u})}{d \underline{u}} \text { is decreasing in } \underline{u},
$$

assuming that $\gamma(y)$ is strictly positive for at least one state $y$ in the $\alpha$-problem described by $(\underline{u}, \ldots, \underline{u})$.

However,

$$
\frac{d M(\underline{u}, \ldots, \underline{u})}{d \underline{u}}=\sum_{y} \frac{\partial M(\underline{u}, \ldots, \underline{u})}{\partial \underline{u}(y)}=-\sum_{y} \gamma(y) .
$$

Combining (13) and (14), the proof is complete.

Lemma 3. The lender's payoff for some allocation of power $\alpha \in[0,1]$ is no smaller than its payoff for any allocation of power $\alpha^{\prime} \geq \alpha$.

Proof. Take two values $\alpha_{1}, \alpha_{2} \in(0,1)$ with $\alpha_{2} \geq \alpha_{1}$. Let $\left(u_{1}, \pi_{1}\right)$ and $\left(u_{2}, \pi_{2}\right)$ be the corresponding sets of borrower-lender payoff pairs. Since the feasible set is unchanged, a simple revealed preference argument tells us that

$$
\begin{aligned}
& \alpha_{1} u_{1}+\left(1-\alpha_{1}\right) \pi_{1} \geq \alpha_{1} u_{2}+\left(1-\alpha_{1}\right) \pi_{2} \\
& \alpha_{2} u_{2}+\left(1-\alpha_{2}\right) \pi_{2} \geq \alpha_{2} u_{1}+\left(1-\alpha_{2}\right) \pi_{1}
\end{aligned}
$$

Summing these two inequalities and dividing by $\left(\alpha_{2}-\alpha_{1}\right)$, we obtain:

$$
\left[\pi_{1}-\pi_{2}\right] \geq\left[u_{1}-u_{2}\right]
$$

This inequality must imply that $\pi_{1} g e \pi_{2}$. For if not, then $\pi_{1}<\pi_{2}$ and so $u_{1}<u_{2}$, which contradicts (constrained) Pareto-optimality of solutions to the $\alpha$-problem.

We say that an allocation $\mathbf{c}$ is non-trivial if $\mathbf{c} \neq \mathbf{y}$. Consider a mean-preserving spread in the income distribution in which the lowest possible income realization call it $y$ - decreases by a small amount $\epsilon>0$, while the other income realizations are increased by $\epsilon d y$ for $y>\underline{y}$ such that $\sum_{y>\underline{y}} p(y) d y=p(\underline{y})$.

Lemma 4. If credit markets are competitive and the initial allocation is non-trivial, then there exists a mean-preserving spread in the income distribution such that

$$
(1-\delta) u(y)+\delta \sum_{z} p(z) u(z)
$$

declines for all $y$, provided that $\epsilon$ is small enough. 
Proof. Assume that the constrained optimal allocation is non-trivial, $\mathbf{c}^{*} \neq \mathbf{y}$, and let $\mathbf{t}^{*}=\mathbf{y}-\mathbf{c}^{*}$. First notice that the expected utility $E u(\mathbf{t}) \equiv \sum_{y} p(y) u(y-t(y))$ and

$$
V(y, \mathbf{t}) \equiv(1-\delta) u(y-t(y))+\delta E u(\mathbf{t})
$$

are strictly concave in $\mathbf{t}$. Moreover, notice that $E u(0)=\underline{u}$ and $V(y, 0)=(1-$ $\delta) u(y)+\delta \underline{u}$. And at $t^{*}$, we know that $E u\left(\mathbf{t}^{*}\right) \geq \underline{u}$ and $V\left(y, \mathbf{t}^{*}\right) \geq(1-\delta) u(y)+\delta \underline{u}$. It follows that, for any $\lambda \in(0,1)$, the borrower's participation constraint (4) and incentive constraints (1) hold with a strict inequality at $\mathbf{c}_{\lambda}=\mathbf{y}-\lambda \mathbf{t}^{*}$. In addition, the allocation $\mathbf{c}_{\lambda}$ would still satisfy the lender's participation constraint.

Hence, it must be that, at $\lambda=0, \partial V\left(y, \lambda \mathbf{t}^{*}\right) / \partial \lambda>0$, that is

$$
-(1-\delta) u^{\prime}(y) t^{*}(y)-\delta \sum_{s} p\left(y_{s}\right) t^{*}\left(y_{s}\right) u^{\prime}\left(y_{s}\right)>0
$$

Denoting $S^{+}$and $S^{-}$the sets of state $s$ in which $t^{*}\left(y_{s}\right)>0$ and $t^{*}\left(y_{s}\right)<0$ respectively, we can rewrite $(15)$ as

$$
-(1-\delta) u^{\prime}(y) t^{*}(y)-\delta \sum_{s \in S^{+}} p\left(y_{s}\right) t^{*}\left(y_{s}\right) u^{\prime}\left(y_{s}\right)+\delta \sum_{s \in S^{-}} p\left(y_{s}\right)\left|t^{*}\left(y_{s}\right)\right| u^{\prime}\left(y_{s}\right)>0
$$

The credit market being competitive, we know that $\sum_{s} p\left(y_{s}\right) t^{*}\left(y_{s}\right)=0$ in equilibrium, so that

$$
\sum_{s \in S^{-}} p\left(y_{s}\right)\left|t^{*}\left(y_{s}\right)\right|=\sum_{s \in S^{+}} p\left(y_{s}\right) t^{*}\left(y_{s}\right) .
$$

Since $u^{\prime}(\underline{y})>u^{\prime}\left(y_{s}\right)$ for all $y_{s}>\underline{y}$, it follows that

$$
\sum_{s \in S^{+}} p\left(y_{s}\right) t^{*}\left(y_{s}\right) u^{\prime}(\underline{y})>\sum_{s \in S^{-}} p\left(y_{s}\right)\left|t^{*}\left(y_{s}\right)\right| u^{\prime}\left(y_{s}\right)
$$

Therefore, (15) implies that

$$
-(1-\delta) u^{\prime}(y) t^{*}(y)+\delta \sum_{s \in S^{+}} p\left(y_{s}\right) t^{*}\left(y_{s}\right)\left[u^{\prime}(\underline{y})-u^{\prime}\left(y_{s}\right)\right]>0
$$

Now, consider the following change in the income distribution for all state $s$

$$
d y_{s}=\left\{\begin{array}{l}
-\epsilon \\
\epsilon t^{*}\left(y_{s}\right) /\left[\sum_{s^{\prime} \in S^{+}} p\left(y_{s}^{\prime}\right) t^{*}\left(y_{s}^{\prime}\right)\right] \quad \text { if }\left\{\begin{array}{l}
y_{s}=y \\
s \in S^{+} \\
0
\end{array}\right. \text { otherwise }
\end{array}\right.
$$

Clearly, this is a mean-preserving spread in income since $\sum_{s} p\left(y_{s}\right) d y_{s}=0$. Moreover, inequality (16) implies that such mean-preserving spread in income results in 
a decrease in $(1-\delta) u(y)+\delta \sum_{z} p(z) u(z)$ for all $y$ provided that $\epsilon$ is small enough.

Georgetown University

E-mail address: gg58@georgetown.edu

$U R L:$ http://www.georgetown.edu/faculty/gg58

New York University and Instituto de AnÁlisis Económico (CSIC)

E-mail address: debraj.ray@nyu.edu

$U R L$ : http://www.econ.nyu.edu/user/debraj 